\title{
O Imaginário Urbano sobre Fotografia e Morte em Belo Horizonte, MG, nos Anos Finais do Século $\mathbf{X X}^{\star}$
}

\author{
The Urban Imaginary on Photography \\ and Death in Belo Horizonte, Minas Gerais, \\ in the Final Years of the XX Century
}

MAURO GUILHERME PINHEIRO KOURY Doutor em Ciências Sociais pela Universidade de Glasgow, Scotland; Professor do Depto de Ciências Sociais/ UFPB ** GREM/UFPB - Caixa Postal 5144, 58050-970, João Pessoa - Paraíba maurokoury@terra.com.br

\begin{abstract}
RESUMO Como responderiam à questão do uso da fotografia mortuária os habitantes urbanos moradores das capitais dos estados brasileiros no final do século vinte? É essa a pergunta principal deste artigo, tendo como limite geográfico a cidade de Belo Horizonte, capital do estado de Minas Gerais. Nele se busca traçar um perfil do comportamento urbano brasileiro e, aqui, especificamente, de Belo Horizonte, sobre a morte e o

\footnotetext{
Artigo recebido em 18/11/2005. Autor Convidado.

* O autor é Coordenador do GREI - Grupo Interdisciplinar de Estudos em Imagem e do GREM - Grupo de Estudo e Pesquisa em Antropologia e Sociologia da Emoção/UFPB
} 
morrer no final do século vinte, bem como o papel da fotografia na lapidação e direção desse contorno.

Palavras-Chave Fotografia Mortuária, Belo Horizonte, História dos Costumes

ABSTRACT As the urban inhabitants of the capitals of the Brazilian states in the end of twenty century would answer the question of the use of the mortuary photograph, it is the main question of this article, having as geographic limit the city of Belo Horizonte, capital of the state of Paraíba. This paper searches to trace a profile of Brazil's urban behavior on the death and dying in the end of twenty century, as well as the role of the photograph in the stonecutting and route of this shape.

Key words Mortuary Photography, Belo Horizonte, History of Costums

Este artigo busca compreender as atitudes no Brasil contemporâneo sobre a sociabilidade urbana em relação ao luto e aos rituais da dor de quem perde um ente querido, especificamente, levantar algumas questões sobre o uso da fotografia mortuária na cidade de Belo Horizonte, capital de Minas Gerais, ou sobre sua existência nos álbuns de família locais. O universo é formado por um conjunto de setenta (70) informantes, moradores da cidade de Belo Horizonte, MG, e faz parte de uma pesquisa maior sobre Luto e Sociedade no Brasil, onde foram entrevistados 1304 informantes nas vinte e sete capitais de estados do Brasil, entre os anos de 1994 a $2001 .^{1}$

A fotografia mortuária, assim, entrou no rol de perguntas de um questionário padronizado como uma espécie de adendo, visando satisfazer uma curiosidade de uma outra linha de pesquisa, ${ }^{2}$ também, por mim coordenada. Como responderiam a questão sobre o uso da fotografia mortuária os habitantes urbanos moradores das capitais dos estados brasileiros no final do século vinte, era a questão adendo, que se queria alcançar.

No Brasil, somente uma pequena parcela dos entrevistados, afirmou o uso da fotografia mortuária. O conjunto dos que responderam afirmativamente foi de 271 informantes, no total de 1304 respondentes, ou seja, ocupou apenas $20,78 \%$ do conjunto da amostra. A cidade de Belo Horizonte representou apenas 5,37\% do total da amostra nacional, em

1 Ver o resultado final desta pesquisa no meu livro KOURY, Mauro Guilherme Pinheiro. Sociologia da Emoção. O Brasil Urbano sob a Ótica do luto. Petrópolis: Vozes, 2003.

2 Na pesquisa intitulada Sobre os Silêncios da Fotografia, em desenvolvimento no GREI. 
um total de setenta (70) informantes. Em relação à fotografia mortuária, somente nove entrevistados certificaram seu uso de forma afirmativa. $O$ que perfaz um total percentual de $12,86 \%$ de respondentes, em relação aos setenta entrevistados na cidade, que disseram ter o costume de fotografar os seus mortos (Tabela 1), ficando, pois, na média percentual do conjunto de cidades pesquisadas.

Tabela 1 - Cidade de Belo Horizonte e o uso da fotografia mortuária

\begin{tabular}{|c|c|c|c|c|c|c|}
\hline \multirow{2}{*}{ Cidade } & \multicolumn{2}{|c|}{ Total } & \multicolumn{2}{|c|}{ Não } & \multicolumn{2}{|c|}{ Sim } \\
\hline & $\mathrm{N}$ & $\%$ & $\mathrm{~N}$ & $\%$ & $\mathrm{~N}$ & $\%$ \\
\hline Belo Horizonte & 70 & 100 & 61 & 87,14 & 9 & 12,86 \\
\hline
\end{tabular}

A pergunta adendo trouxe uma surpresa ao mostrar que, dentro de um quadro geral de expectativas sobre etiquetas sociais, o Brasil urbano apresenta-se bastante uniforme. Parti de uma hipótese inicial de trabaIho de que quanto maior a cidade menor seria o hábito da fotografia mortuária. O que se deu, contudo, foi um equilíbrio de respostas entre as diversas capitais pesquisadas, com uma média percentual, por cidade, de 18 a 25\% de afirmações sobre o hábito de fotografar os entes queridos mortos, sobre uma média nacional de $20,78 \%{ }^{3}$

\section{Breve caracterização dos informantes}

Uma breve caracterização dos setenta informantes de Belo Horizonte se faz necessário para uma compreensão melhor de suas respostas à questão da fotografia mortuária de cunho privado.

Dos setenta entrevistados, $62,86 \%$ eram do sexo feminino, contra $37,14 \%$ do sexo masculino. Cruzados com a idade, o perfil dos informantes de Belo Horizonte assim se apresenta: dez por cento (10\%) dos entrevistados possuíam idade entre 15 a 25 anos, sendo que destes, 8 , $57 \%$ eram do sexo feminino contra $1,43 \%$ do sexo masculino. Entre os que possuíam, na época da aplicação dos questionários, entre 26 a 39 anos, $31,43 \%$ - 18,57\% eram mulheres-contra $12,86 \%$ de homens. Trinta respondentes, $42,86 \%$ da amostra, situavam-se na faixa etária de 40 a 59 anos sendo, destes, $28.57 \%$ do sexo feminino contra $14,29 \%$ do

3 Como melhor pode ser visto em KOURY, Mauro Guilherme Pinheiro. Você fotografa os seus mortos?. In: Koury, M. G. P. (org.). Imagem e Memória: Ensaios em Antropologia Visual. Rio de Janeiro: Garamond, 2001, p. 51 a 94. 
sexo masculino. Na faixa etária com mais de sessenta anos, 15,71 respondentes, $7,15 \%$ eram mulheres contra $8,56 \%$ de homens.

Conforme pode ser visto na Tabela 2 abaixo, contudo, o núcleo maior de respondentes concentrou-se nas faixas etárias correspondentes a 26 e 39 e 40 a 59 anos. Juntas, as duas faixas correspondem a 74,29\% da amostra. ${ }^{4}$

\section{Tabela 2 - Cidade de Belo Horizonte: Entrevistados por Sexo e Idade}

\begin{tabular}{|c|c|c|c|c|c|c|}
\hline \multirow{2}{*}{ Idade } & \multicolumn{2}{|c|}{ Total } & \multicolumn{2}{|c|}{ Feminino } & \multicolumn{2}{|c|}{ Masculino } \\
\hline & $\mathrm{N}$ & $\%$ & $\mathrm{~N}$ & $\%$ & $\mathrm{~N}$ & $\%$ \\
\hline 15 a 25 anos & 7 & 10,00 & 6 & 8,57 & 1 & 1,43 \\
\hline 26 a 39 anos & 22 & 31,43 & 13 & 18,57 & 9 & 12,86 \\
\hline 40 a 59 anos & 30 & 42,86 & 20 & 28,57 & 10 & 14,29 \\
\hline 60 anos e mais & 11 & 15,71 & 5 & 7,15 & 6 & 8,56 \\
\hline Total & 70 & 100 & 44 & 62,86 & 26 & 37,14 \\
\hline
\end{tabular}

A escolaridade, por seu turno, encontra-se distribuída do seguinte modo: de $13,92 \%$ concluiram o primeiro grau; $54,28 \%$ o segundo grau e $32,86 \%$ dos respondentes o superior completo. Como se pode ver na Tabela 3, os indivíduos que optaram por responder à pesquisa possuem, em sua maioria, uma educação formal acima da média brasileira, sendo especificamente pertencentes às classes médias e altas.

Tabela 3 - Cidade de Belo Horizonte: Entrevistados por Escolaridade

\begin{tabular}{ccc}
\hline \multicolumn{3}{c}{ Tabela 3 - Entrevistados por Escolaridade } \\
\hline Escolaridade & $\mathrm{N}$ & $\%$ \\
\hline Primeiro Grau & 9 & 12,86 \\
Segundo Grau & 38 & 54,28 \\
Superior & 23 & 32,86 \\
Total & 70 & 100 \\
\hline
\end{tabular}

Quanto à renda, 51,43\% estão situados na faixa de 06 a 10 sm, 35,71\% na faixa de 11 a $20 \mathrm{sm}$. As duas faixas, quando juntas, perfazem o total

4 É interessante salientar, contudo, que apenas na faixa etária superior aos sessenta anos, os homens superaram as mulheres em número de respostas, 6 homens para 5 mulheres, no total de 11 respondentes, em um questionário sobre o processo de luto. 
de $87,14 \%$ da amostra. 5,71\% estão na faixa acima de $21 \mathrm{sm}$, e 7,14\% na faixa de 01 a 05 sm (Tabela 4). O que confirma a opinião acima atribuída quanto à inserção dos entrevistados da cidade de Belo Horizonte nas classes médias e altas.

Tabela 4 - Cidade de Belo Horizonte: Entrevistados por Faixa de Renda

\begin{tabular}{ccc}
\hline \multicolumn{3}{c}{ Tabela 4 - Entrevistados por Faixa de Renda } \\
\hline & $\mathrm{N}$ & $\%$ \\
\hline 01 a 05 sm & 5 & 7,14 \\
06 a 10 sm & 36 & 51,43 \\
11 a 20 sm & 25 & 35,71 \\
21 sm e mais & 4 & 5,71 \\
Total & 70 & 100 \\
\hline
\end{tabular}

As profissões, porém, são as mais variadas, havendo um equilíbrio entre elas. Vai do aposentado e da dona de casa ao estudante; de empresário a comerciante, de profissional liberal e professor a funcionário público e militar. As profissões de trabalhador de nível médio e manual obtiveram os menores percentuais, juntas somando $11,45 \%$ dos entrevistados, conforme pode ser visto na tabela 5.

Tabela 5 - Cidade de Belo Horizonte: Entrevistados por Profissão

\begin{tabular}{lcc}
\hline \multicolumn{3}{c}{ Tabela 5 } \\
\hline Profissão Entrevistado por Profissão \\
\hline Aposentado & $\mathrm{N}$ & $\%$ \\
Dona de casa & 10 & 14,28 \\
Empresário Comerciante & 10 & 14,28 \\
Estudante & 12 & 17,14 \\
Funcionário Público e Militar & 7 & 10,00 \\
Professor e Profissões Liberais & 9 & 12,85 \\
Trabalhador Nível Médio & 14 & 20,00 \\
Trabalhador Manual & 6 & 8,60 \\
Total & 2 & 2,85 \\
& 70 & 100.00 \\
\hline
\end{tabular}

De acordo com a tabela 6, 98,57\% dos informantes freqüentam religião, contra 1,43\% que afirmam não possuir qualquer tipo de religião. Dos entrevistados que aceitam alguma forma de religiosidade, $77,14 \%$ são católicos, 17,14\% evangélicos e 4,29\% de outras religiões (religiões orientais, espiritismo, religiões afro-brasileiras, entre outras). 
Tabela 6 - Cidade de Belo Horizonte: Entrevistados por Religião

\begin{tabular}{ccc}
\hline & Tabela 6 - Entrevistados por Religião \\
\hline Religião & $N$ & $\%$ \\
\hline Católica & 60 & 85,71 \\
Evangélica & 6 & 8,57 \\
Outras & 3 & 4,29 \\
Não Possui & 1 & 1,43 \\
Total & 70 & 100 \\
\hline
\end{tabular}

Perguntados se possuem o hábito de fotografar os seus mortos, $87,14 \%$ afirmou que não, contra $12,86 \%$ que disseram ter o costume da fotografia mortuária, conforme apresentados na tabela 1 acima. Estes dados cruzados com os sobre religião, porém, fornece um quadro interessante, conforme pode ser visto na tabela 7 .

Tabela 7 - Cidade de Belo Horizonte: Religião versus Fotografa os Mortos

\begin{tabular}{ccccccccccc}
\hline \multicolumn{7}{c}{ Tabela 7 } & \multicolumn{7}{c}{ Religião versus Fotografa os Mortos } \\
\hline Religião & \multicolumn{1}{c}{ Católica } & \multicolumn{1}{c}{ Evangélica } & Outras & Sem Religião & \multicolumn{2}{c}{ Total } \\
\hline Fotografa os Mortos & $\mathrm{N}$ & $\%$ & $\mathrm{~N}$ & $\%$ & $\mathrm{~N}$ & $\%$ & $\mathrm{~N}$ & $\%$ & $\mathrm{~N}$ & $\%$ \\
\hline Sim & 8 & 13,3 & - & - & 1 & 33,3 & - & - & 9 & 12,9 \\
Não & 52 & 86,7 & 6 & 100 & 2 & 66,7 & 1 & 100 & 61 & 87,1 \\
Total & 60 & 100 & 6 & 100 & 3 & 100 & 1 & 100 & 70 & 100 \\
\hline
\end{tabular}

A totalidade dos que afirmam uma religião evangélica afirmou não possuir o hábito da fotografia mortuária (Tabela 7). Muitos deles alegaram, inclusive a diabolização presente no costume,

esse negócio de guardar o morto em fotografia é coisa do diabo que quer que a gente se apegue às coisas do mundo, condenando os mortos ao reino do inferno para uma ganância dos vivos, ${ }^{5}$

conforme o depoimento às margens do questionário de um entrevistado, engenheiro mecânico e dono de uma pequena metalúrgica. $\mathrm{O}$ ato de fotografar os mortos, assim, parece ser condenado pelas Igrejas Evangélicas por conduzi a um apego mundano, na tentativa de retenção do morto através do retrato. Quem assim o faz, peca, sobretudo, por conde-

5 Questionário 1017, respondente masculino, 45 anos, evangélico da Igreja Universal do Reino de Deus. 
nar o morto ao inferno, tendo como conseqüência pessoal nunca poder aspirar à salvação.

São sobretudo os católicos, como pode ser verificado na tabela 7 , que atestam a afirmação do uso da prática da fotografia de seus entes queridos mortos, 8 respondentes, ou 13,33\% dos sessenta que se declararam católicos. A fotografia mortuária parece, deste modo significar, para os católicos e praticantes da fotografia mortuária, uma forma de reter a face do morto em sua melhor expressão. Como uma espécie de costume retido mas distanciado de sua origem, ligado a idéia da boa morte, costume medieval que buscava diagnosticar através da face do morto se ele chegaria em paz no céu, e se tinha cumprido todos os compromissos terrenos antes da hora do trespasse. ${ }^{6}$

\section{A fotografia mortuária}

Antes de aprofundar a questão da uniformidade do imaginário brasileiro de etiquetas sociais contemporâneo, cabe responder a questão inicial do que é fotografia mortuária. Por fotografia mortuária se está entendendo o registro fotográfico que tem por função preservar o corpo morto de um ente querido para a posteridade, na hora final de despedida, antes do sepultamento. Ela faz parte de um conjunto fotográfico, de cunho privado e íntimo, que se convencionou chamar de retratos ou álbuns de família.

Nestes álbuns ou coleções de retratos estão fixados momentos considerados importantes no cotidiano familiar, e que de alguma forma representa uma passagem ou um estágio característico na vida da família e dos seus entes. Nascimentos, aniversários, formaturas, casamentos e mortes, entre outras datas significativas para cada família específica, podem fazer parte dessa coleção.

Momentos felizes e momentos tristes são registrados na tentativa de conservar e relembrar os laços de intimidade e os laços sociais da família para si e para a sociedade em geral.

No início, ainda no século XIX, o registro fotográfico ficava restrito a membros de famílias abastadas pelo alto custo da fotografia. Com a entrada do século XX e o passar de suas décadas, a fotografia torna-se mais barata e o seu uso se alastra por todos os segmentos sociais. Dáse uma espécie de democratização do uso da fotografia, com o acesso possível a todo e qualquer cidadão.

A fotografia no correr do século XX, principalmente, começa a fazer parte da vida do cidadão comum, tanto na vida pública - como prova

6 Ver sobre o assunto : ARIĖS, Philippe. Images de l'Homme devant la Mort. Paris: Seuil, 1983. 
da existência e da confirmação de um sujeito específico, como registros documentais que vão desde a cédula de identidade até os registros policiais -, como na vida privada. Ao nível privado, ela vai se assentar como uma espécie de fixação de laços de parentesco ou mesmo de um tipo de eternização sentimental e afetiva da rede familiar.

No Brasil, e em Minas Gerais, e na cidade de Belo Horizonte, especificamente, a fotografia mortuária surge logo após o aparecimento da fotografia como arte e como técnica de registro e fixação de um presente passado específico. Sua popularização, contudo, vai se dar entre os anos de 1920 e 1950, quando é utilizada por várias camadas da população.

Deve-se, contudo, distinguir a fotografia mortuária dos cartões distribuídos logo após a missa de sétimo dia também conhecido pelo nome de santinhos. Estes últimos podem vir acompanhados de fotografia dos entes mortos ou não. Quando acompanhados, porém, de fotografias, os retratos apresentam sempre a pessoa em vida. Escolhe-se, geralmente, a foto que melhor represente a pessoa em vida, em sua melhor performance, para ilustrar os santinhos.

A fotografia mortuária, por outro lado, representa a pessoa no ato da morte. É a morte que é registrada, a ação do morrer que é buscada fixar como uma forma de rememoração de um acontecimento singular no interior de uma família especifica.

A pessoa morta, na cama ou em um sofá, já com suas vestes funerárias, como se estivesse a dormitar, ou o morto no caixão adornado com flores, mãos cruzadas com um terço ou uma cruz em oração, sozinho ou acompanhado de parentes mais próximos, fazem parte do cenário do registrar fotograficamente os mortos queridos. Outras fotos mortuárias retratam o morto durante o velório ou no cemitério rodeado dos parentes, amigos e pessoas influentes da comunidade.

Em todas elas um conjunto de convenções indica não apenas a boa morte, ou a morte tranqüila, mas também o luto, a dor impressa no rigor das vestes e nas expressões dos que ficam. Indicam também a importância do morto, e de sua família, na comunidade. A rememoração dos mortos, através do ato fotográfico, assim, era um momento de representação do morto na família e na sociedade. Bem como, uma representação da família do morto na sociedade, como indicador da importância do seu morto ou da estrutura familiar onde ele se encontra inserido na estrutura de poder societária.

Com a democratização do uso da fotografia, e da fotografia mortuária em particular, a utilização do registro deixou cada vez mais de ser feito por profissionais da fotografia e passou a ser realizado pelos próprios membros da família; por fotógrafos amadores, portanto. Uma grande perda dos elementos simbólicos contidos na fotografia mortuária então se deu. 
As convenções simbólicas contidas nos registros profissionais cederam lugar para o registro in loco do corpo morto. Perdeu-se, ou enevoou-se em brumas, as etiquetas ou os símbolos representativos do imaginário religioso que envolvia o cenário da fotografia mortuária, o ar de representação, para, em seu lugar, aparecer o registro exclusivo da morte. Como algo que se quer reter, sem prestar muita atenção a conteúdos estéticos ou de símbolos que buscavam representar algo além do que o registro específico do morto. Que procuravam fixar os entes queridos mortos sem se importarem com as convenções ritualísticas da dor e da morte em sociedade que estilizaram as fotografias mortuárias nas primeiras décadas do século XX.

A generalização do uso da câmera fotográfica nos anos de 1950 em diante, e o acesso amador à fotografia se, por um lado, consolidou o instrumento técnico fotografia no seio da sociedade, por outro lado, quebrou também o encantamento que envolvia todo o simbolismo ritualístico da construção fotográfica, sem perder, contudo, a sua eficácia de prova de acontecimento ou da existência do objeto retratado em um tempo e em um espaço singular determinado. A fotografia parece assegurar, cada vez mais, a noção de passado. De momentos significantes a serem guardados no registro de uma vida singular.

A ampliação do uso fotográfico por todas as camadas sociais, assim, parece ter acompanhado todo um processo de mudança de costumes e modo de ação do homem comum e das etiquetas sociais. No caso da fotografia mortuária, a perda da aura ritualística que a envolvia foi se dando pari passu ao processo de expansão do uso da fotografia por amplos setores sociais.

A morte e o luto foram se tornando, cada vez mais, aspectos privados da vida e circunscritos ao elo familiar menor, a família nuclear. $\mathrm{O}$ que parece ter implicado no abandono da freqüência do hábito pelos setores mais abastados e da classe média mais intelectualizada da sociedade que passaram, em grande medida, a ver nele um apelo mórbido individual ao morto e à morte. Logo seguido pelas classes média baixa e baixa.

A fotografia mortuária vista como sinônimo de morbidez por parte de quem a tira ou a conserva, assumiu assim um ar de exclusão social da legião de costumes que norteiam a prática social. Começou a ser interpretada como um fenômeno de atraso e de incivilidade, no sentido que Norbert Elias ${ }^{7}$ dá ao termo civilização, contrário ao desapego e a secularização da morte na modernidade, ou como um aspecto doentio da personalidade individual que precisava ser tratado.

7 ELIAS, Norbert. O Processo Civilizador. São Paulo: Zahar, 1990 e 1993. 2v. 
Ela aparentemente desaparece do rol de etiquetas social e do "bom tom" do homem contemporâneo civilizado brasileiro nos meados dos anos de 1960 e, principalmente, dos anos de 1970 em diante. Assim, não foi com surpresa alguma que se atestou, na tabela 8 , os $79,22 \%$ de respostas negativas à prática da fotografia mortuária no levantamento realizado entre habitantes urbanos dos vinte e sete estados brasileiros, entre os anos de 1994 a 2001. Ou dos 4,68\% dos entrevistados da cidade de Belo Horizonte, em relação ao Brasil.

As respostas sobre o porque não fotografavam os seus mortos, parecem interessante porque aparentam representar mais do que a resistência aparente dos $20,78 \%$ brasileiros habitantes das capitais dos vinte e seis estados e distrito federal, ou 0,69\% de Belo Horizonte em relação ao conjunto dos informantes do país que afirmaram à prática e o uso da fotografia mortuária, conforme pode ser visto na tabela 8.

\section{Tabela 8 - Cidade de Belo Horizonte: Fotografa os Mortos - comparação com o Brasil}

\begin{tabular}{|c|c|c|c|c|c|c|}
\hline \multicolumn{7}{|c|}{ Tabela 8 - Fotografa os Mortos: Brasil versus Belo Horizonte } \\
\hline \multirow{2}{*}{ Cidade } & \multicolumn{2}{|c|}{ Total } & \multicolumn{2}{|c|}{ Não } & \multicolumn{2}{|c|}{ Sim } \\
\hline & $\mathrm{N}$ & $\%$ & $\mathrm{~N}$ & $\%$ & $\mathrm{~N}$ & $\%$ \\
\hline Belo Horizonte & 70 & 100 & 61 & 4,68 & 9 & 0,69 \\
\hline Brasil & 1304 & 100 & 1033 & 79,22 & 271 & 20,78 \\
\hline
\end{tabular}

Este conjunto de respostas pode ajudar a traçar um perfil do comportamento urbano brasileiro, e aqui especificamente de Belo Horizonte, sobre a morte e o morrer no final do século vinte, bem como o papel da fotografia na lapidação e direção desse contorno.

\section{Porque não fotografar os mortos}

Perguntados sobre o porque não fotografavam os seus entes queridos mortos, muitos dos entrevistados responderam que preferiam lembrar a pessoa viva, e informaram que buscavam evitar recordações da dor. Nas duas categorias de respostas, a morte e o corpo morto parecem estar associados a algo que se quer ou se deve esquecer.

A tendência atual em relação à morte e ao morrer é, deste modo, a de um sentimento de ambivalência onde se misturam a solidão e a vergonha de se mostrar em dor. ${ }^{8}$ A morte enquanto categoria de entendi-

8 Como indicam estudos clássicos de autores como ELIAS, Norbert. La Soledad de los Moribundos. $2^{\underline{a}}$ edição, México: Fondo de Cultura Económica, 1989; THOMÁS, Louis-Vicent. Antropologia de la Morte. México: Fondo 
mento humano parece tender a ser banida de sua face social em contraposição às categorias de técnica e de dominação.

Para o homem moderno, segundo esses autores, a morte passa cada vez mais a ser entendida enquanto possibilidade de ser vencida, domada. A sua não domesticação, nos dias atuais, é sentida em um misto de ansiedade de a vencer e de ansiedade de ainda não tê-la domada. Dupla ansiedade que é repassada para o homem comum e para o imaginário moderno como vergonha de ser por ela tocado.

A morte e o morrer passam a ser representados na ou através da agilidade funcional das instituições atuais que com eles lidam profissionalmente. A medicina, a indústria funerária, a burocracia de registros de óbitos, as vias por onde escorrem os corpos até o sepultamento, tanto quanto as instituições que lidam com os que ficam e com o luto, buscam tratar o ato da morte de forma a mais higiênica possível e que afete da menor maneira possível o cotidiano de uma sociabilidade.

O sentimento de ser tocado pela morte de alguém se torna um sentimento envergonhado. A dor causada pelo falecimento de um ente querido torna-se assim, ao mesmo tempo, um sentimento profundo de dor e solidão e um sentimento interiorizado de difícil expressão. Interiorização onde se busca esconder a dor pessoal com medo de contaminar o próximo. $^{9}$

O outro também, encastelado em seu universo pessoal fechado, não sabe como expressar seus sentimentos para os enlutados, para os que estão em dor, e recolhe-se e esconde-se daqueles que vivenciam uma perda. O que aumenta a solidão de ambos.

O sentimento de vergonha e recolhimento, assim, afastam as pessoas umas das outras, como se a emoção pudesse macular as relações sociais. Expulsa do social, a emoção parece satisfazer-se, desse modo, como intimidade, como um sentimento que se quer expressar, se quer ter e obter do outro, mas que não se consegue. Como um hiato sempre maior entre o indivíduo social e a sociedade a que ele pertence, aos outros sociais.

A lembrança do outro vivo, ou o esquecimento da dor parecem pontuar assim o imaginário de hoje do habitante de Belo Horizonte, tanto quanto da sociedade brasileira e da ocidental contemporânea. Nele, o lidar envergonhado com o sentimento da perda, de ser tocado por ele ou ser por ele contaminado, e o receio da morte e sua busca de expulsão

de Cultura Económica, 1983; ARIĖS, Philippe. The Hour of Our Death. New York: Alfred A. Knopf, 1981; MORIN, Edgar. O Homem e a Morte. 2ª ed. Lisboa: Publicações Europa-América, 1988, entre outros estudiosos do comportamento do homem moderno ocidental.

9 Sobre esta discussão ver KOURY, Mauro Guilherme Pinheiro. Cultura e Subjetividade: Questões Metodológicas sobre a Relação Luto e Sociedade. In: Koury, M.G.P. (org.). Cultura \& Subjetividade. João Pessoa: Ed. Universitária, 1996, p.29-44. 
do social, estão expressos. O processo de solidão pontua o sentimento do indivíduo que se vê sujeito pela secularização do processo de morte na sociabilidade local.

A tabela 9, abaixo, retrata as respostas à pergunta feita aos sessenta e um (61) informantes de Belo Horizonte sobre o porque não fotografam os seus mortos que responderam negativamente. As respostas se dividem em várias categorias lógicas como 'a religião não permite', a 'diabolização do mundo', o 'evitar recordações da dor', 'desrespeito ao morto', 'medo' e 'falta de interesse'.

\section{Tabela 9 - Cidade de Belo Horizonte: Porque Não Fotografa os Mortos}

\begin{tabular}{|c|c|c|}
\hline \multicolumn{3}{|c|}{ Tabela 9 - Por que não fotografam os mortos? } \\
\hline Por que não fotografa? & $\mathrm{N}$ & $\%$ \\
\hline Religião não permite & 10 & 14,28 \\
\hline Diabolização do mundo & 5 & 7,14 \\
\hline Evitar recordações da dor & 9 & 12,86 \\
\hline Desrespeito ao morto & 13 & 18,57 \\
\hline Medo & 2 & 2,86 \\
\hline Falta de interesse & 22 & 31,43 \\
\hline Fotografam & 9 & 12,86 \\
\hline Total & 70 & 100 \\
\hline
\end{tabular}

As respostas dos que não utilizam a fotografia mortuária relacionadas com problemas de ordem religiosa se dividem em três subcategorias. A primeira, mais geral, informa que a 'religião não permite', com $14,28 \%$ dos entrevistados, a segunda afirma que a fotografia mortuária é um 'desrespeito ao morto', com 18,57\% das respostas. A terceira, por fim, fala sobre a 'diabolização do mundo' motivada pelo uso da fotografia mortuária, com $7,14 \%$ das respostas. As três subcategorias somadas informam um total de 39,99\% dos respondentes, isto é, 28 entrevistados.

Neste tipo de informação, a religião, aparece como ainda muito forte na definição de princípios morais de quase quarenta por cento dos entrevistados de Belo Horizonte. No caso específico, a religião enquanto uma instância mais pessoalizada, ou seja, que aparece como superior ao indivíduo, informando e normatizando as condutas individuais, parece atuar como o principal centro de referência e informação do sujeito com relação à fotografia mortuária.

A 'diabolização do mundo' mostra um temor em relação à vida depois da morte, em analogia direta ao morto e fundamentalmente aos vivos que buscam formas de sua retenção, mesmo que em imagem foto- 
gráfica, na terra. Esta relacionada, também com a categoria de 'desrespeito aos mortos'. Ambas categorias parecem pertinentes com a esfera da dessacralização da morte representada no ato simbólico da fotografia, com os malefícios que podem causar para o bem estar celeste dos mortos, e para a salvação e possível intermediação do morto com o além para com os que ficaram.

A categoria de desrespeito aos mortos é informada por 18,57\% dos entrevistados de Belo Horizonte. Nela, a fotografia mortuária parece representar uma atitude de ofensa, um ato de profanação de um corpo morto para os informantes. Como se expressou um informante às margens do questionário:

tirar um retrato de um morto é um ato de profanação do cadáver, é um desrespeito ao morto. Isso, sem dúvida, desencadeia a fúria divina ao avanço do demônio entre os homens. É uma coisa que condenará o morto a ficar preso às coisas terrenas, a não encontrar salvação junto ao Senhor, e que condena os que tiraram ao fogo do inferno. É uma coisa do demônio, um desrespeito. ${ }^{10}$

Mais do que uma atitude ética, o sentimento de desrespeito expresso parece significar uma ação moral, onde o corpo morto é condenado à danação, como uma espécie de diabolização presente no ato em si do registro.

O não uso da fotografia mortuária parece se encontrar preso, assim, a um modo de conduta mais pessoalizado e às amarras de uma atitude relacional. A religião, deste modo, aparece como a instância principal de informação do mundo para os entrevistados, tecendo as redes e dirigindo suas condutas dentro de um viés coletivo que assegura um modo de vida singular no espaço urbano.

Acreditam, porém, outros $12,86 \%$ dos entrevistados que a lembrança do morto, quando em vida, ameniza a solidão e torna possível uma evocação sentimental do que se foi pelos que ficam. Preferem, deste modo, lembrar a pessoa viva e acreditam que a fotografia os leva a recordar a dor da perda. A fotografia mortuária, para esse conjunto de entrevistados, prolonga a dor da perda e é vista como uma atitude mórbida, por fixar a morte como elemento de recordação.

Para esta categoria, a morte se não pode ainda ser domada e venci$\mathrm{da}$, deve ser esquecida. As atitudes que indicam o registro do corpo morto amado são sentidas como doentias, e são olhadas com desdém. Os informantes as interpretam como ingênuas e ligadas ao passado, e

10 Questionário 1017, respondente masculino, 45 anos, evangélico da Igreja Universal do Reino de Deus. 
como tal não civilizada e desumana, e através de uma psicologização do mundo, as explicando como fixação mórbida à morte, e como tal, como atitude que deve ser tratada por especialistas.

Uma outra categoria a ser analisada é a categoria medo que, apesar de conter apenas 2,86\% dos informantes de Belo Horizonte, pode conter uma compreensão aderente à primeira acima esboçada, para a análise do imaginário moderno e urbano no Brasil perante a morte e o morrer. A morte parece ser vista por esse conjunto de entrevistados no seu aspecto mórbido, e a fotografia mortuária parece atestar, nada mais nada menos, do que a morbidez de quem a utiliza.

A morte e o corpo morto parecem inspirar um sentimento de curiosidade e, ao mesmo tempo, um sentido de repugnância e medo, ou mesmo de horror. A morte, através do seu aspecto de morbidez, é vista como distúrbio pessoal de quem a fixa. Talvez porque ao ser alijada do social, ao ter-se perdido os significados ritualísticos sociais e religiosos a que estava envolta em um passado não tão remoto, coube a sua visualização pelos modernos através de uma interpretação dos sentimentos de estagnação, do predicado do fim a que a morte parece remeter no seu sentido físico, de carne. Advindo daí a imagem de putrefação a que um corpo morto é sujeito e a idéia de suspensão do social pela fixidez pessoal de alguém em um corpo morto, ou na imagem de um corpo morto representado.

Em uma última hipótese, como a de não realização de um luto pela retenção da morte em si, pela perda do seu sentido primevo e pelo prosseguir assustador da morte enquanto instância última reparadora. Podese constatar uma tendência do habitante da cidade de Belo Horizonte, nestes anos finais do século XX, a um estranhamento perante atitudes que preservem ou busquem preservar a face dos entes queridos mortos como forma de rememoração.

A fotografia mortuária era usada, no início do século, como uma espécie de lembrança do ente querido e também como uma afirmação social da boa morte do parente próximo - além de uma espécie de atestado de como tão querido e respeitado o ente morto fora - e de que a família também continua sendo após a sua morte. Socialmente diferente, o uso da fotografia mortuária no hoje é vista através de um viés de morbidez, de atitude doentia e até de desrespeito ao morto e aos que ficam.

A mesma significação parece compor do mesmo modo os 31,43\% que responderam não fotografar os seus mortos por falta de interesse. A falta de interesse parece indicar que o passado pouco importa, o tempo é pouco para se perder em guardar memórias para um futuro em construção permanente. O presente também tem pouca significação para parar e tentar reter. Com um potencial de interpretação talvez mais afeta- 
do pelo ar blazé. ${ }^{11}$ O tempo social, aparentemente, parece se encontrar fixado nos compromissos formais que orientarão os projetos individuais de cada sujeito, seja através do processo de concorrência, seja ainda na disputa crescente por um lugar ao sol social.

A morte, o ser tocado pela finitude, é uma hipótese não considerada pelo homem moderno. Um acontecimento que não deverá acontecer jamais para com ele e, quando acontece, é visto como uma espécie de infortúnio do qual se deve sair o mais inteiro possível e o mais rapidamente possível, sem comprometer as relações sociais formais que o levarão a realização de um projeto pessoal. O que parece condenar o trabalho de luto a realizar-se unicamente como desilusão do mundo. Conduta que parece levar para um aumento da indiferença social, expressa nas inter-relações dos sujeitos em cena no social. Parece, também, propor a existência de uma diversidade de atitudes onde cada qual faz o que quer, de um lado, e de outro lado, parece mais uma carência e, ao mesmo tempo, uma indisponibilidade em relação ao trato com o outro da ação. Parece revelar, ainda, uma ambigüidade de conduta que evidencia a desagregação do sujeito individual e a fragmentação de sentimentos coletivos, em sua dor, do social.

A aparente frieza da categoria falta de interesse parece, assim, demonstrar acima de tudo esse ar do tudo sem grande importância que se instala nos processos formais de relações entre os indivíduos sociais na contemporaneidade. Um ar que aparentemente coloca a supremacia do indivíduo moderno em relação ao social, que funda uma barreira de defesa da intimidade de um sujeito, mas que também coloca esse mesmo indivíduo na mais profunda solidão. Para ele a sociedade parece ser apenas o lugar de estabelecimento de laços formais para realização do seu projeto social, onde o seu eu, a sua intimidade deve estar preservada contra o uso de terceiros, mesmo que a custa de uma indizibilidade profunda. Mesmo que a custa de lá no fundo de si mesmo ansiar para ser recolhido e reconhecido e afagado por um outro que nunca acontece, seja pelo recolhimento pessoal, seja pelo recolhimento do outro. Seja pela vergonha de ser de ambos.

Uma atitude de reserva perante a fotografia mortuária, por indiferença ou questões religiosas, e principalmente a conservação da face da morte e da dor entre os que permanecem parece ser a tônica dos 87,14\% informantes que revelaram não fotografar os seus mortos. Por outro lado, $12,86 \%$ deles responderam ainda possuir o costume da fotografia mortuária. O que é ou o que representa o retrato mortuário dos entes queridos para esses entrevistados?

11 De que fala SIMMEL. A metrópole e a vida mental. In: VELHO, O.G. (org.). O Fenômeno urbano. Rio de Janeiro: Guanabara, 1987, p.11-25, quando retrata o indivíduo na metrópole moderna. 


\section{O hábito da fotografia mortuária}

Os entrevistados que informaram ter o costume de fotografar os seus mortos, por seu turno, representam 12,86\% dos entrevistados de Belo Horizonte, como visto acima. As suas respostas situaram o "costume à tradição", 2,86\%, e como uma espécie de última lembrança do ente querido que se foi, $10 \%$, conforme a tabela 10.

\section{Tabela 10 - Cidade de Belo Horizonte: Porque Fotografa os Mortos}

\begin{tabular}{|c|c|c|c|c|c|c|c|c|}
\hline \multicolumn{9}{|c|}{ Tabela 10 - Porque Fotografa os Mortos } \\
\hline \multirow{2}{*}{$\begin{array}{l}\text { Porque } \\
\text { fotografa }\end{array}$} & \multicolumn{2}{|c|}{ Tradição } & \multicolumn{2}{|c|}{ Última lembrança } & \multicolumn{2}{|c|}{ Não Fotografam } & \multicolumn{2}{|c|}{ Total } \\
\hline & $\mathrm{N}$ & $\%$ & $\mathrm{~N}$ & $\%$ & $\mathrm{~N}$ & $\%$ & $\mathrm{~N}$ & $\%$ \\
\hline Total & 2 & 2,86 & 7 & 10 & 61 & 87,14 & 70 & 100 \\
\hline
\end{tabular}

As respostas relacionadas à tradição parecem indicar a manutenção de um hábito familiar, vindo dos antepassados e conservado pelos avós e pelos pais. Muitos dos que sugeriram o seu uso possuem tradições recentes na cidade de Belo Horizonte e no urbano. Conservam, também, uma importante e básica estrutura familiar, onde se situam em rede como pessoas. Parece ser na família que os respondentes, que asseguraram a tradição como uso da fotografia mortuária, se pautam para uma definição de si mesmos e para a configuração de sua pessoa no seu interior, e daí o social.

Outros, pelo contrário, imputam a prática da fotografia mortuária como uma forma de retenção do morto em suas vidas. Como uma busca de obtenção de qualquer coisa, mesmo que seja um registro fotográfico. Registro que se apresente de forma constante como uma última lembrança do parente morto. A fotografia, aqui, parece revelar, então, a sua essência fundamental. A de propor a retenção do passado em instantâneo possível de colecionar, fundando curvas de vida retidas e contidas em álbuns, caixas ou baús de família.

Neste caso, não parece ser apenas a face da morte retratada, mas o processo do morrer. Muitos informam, ao lado do questionário, possuírem o registro fotográfico dos últimos momentos em vida de alguns dos seus entes queridos até a despedida final, quando o caixão é depositado na cova ou na caixa funerária.

Na cidade de Belo Horizonte, é importante notar, existem junto as centrais de velórios, nos cemitérios mais populares, e como tendência do século XXI das modernas propostas das 'moradas da paz', fotógrafos 
profissionais especializados na arte do registro fotográfico mortuário. Nos cemitérios mais populares e nas centrais de velórios circulam entre os enterros ou corpos velados oferecendo aos familiares os seus serviços para o registro final do morto enquanto velado, ou no cortejo até a última morada. Alguns deles revelaram sobreviver basicamente desse tipo de registro, cobrando em média $R \$ 8,50$ (oito reais e cinqüenta centavos), com preços de 2001, por cada foto revelada.

Nas propostas mais modernas de cemitérios, entre outros serviços incluídos, como restaurantes, música ao vivo - normalmente violinos e violoncelo-, psicoterapeutas para acompanhamento das pessoas em luto, existe o setor de fotografia. Quando se adquire o lugar da última morada para o ente querido que se foi, é oferecido todo um pacote que pode ser adquirido ou não por parte do consumidor.

Estas fotografias parecem não servir apenas para rememorar a morte do ente que se foi entre os que estavam próximos na hora dos momentos finais de vida e na morte. Serve também, e sobretudo, para serem enviados para os parentes, próximos ou amigos, que não puderam assistir os momentos finais do ente amado.

A troca de fotografias mortuárias tem o sentido, aqui, ao que parece, de assegurar aos que não puderam acompanhar o desfecho da morte de um parente, a sua morte. A posse, mesmo que visual, do corpo morto, aqui, conforma uma prática de consubstanciação da morte, consentindo a inteireza da introjeção do morto, por assegurar-se do seu morrer. Evocando ao mesmo tempo o reforço de redes familiares no sentido da manutenção e estabilidade dos indivíduos que a ela pertencem, inclusive, nos momentos de dor.

Parece, por fim, ser uma forma de, ao comprovar, pela fotografia, a morte, poder também exercitar o trabalho de luto em sua integridade.

As atitudes perante a morte e o morrer, na cidade de Belo Horizonte, parecem passar por um processo ambivalente de atitudes, que vão desde a aparente indiferença aos rituais tradicionais e à própria morte, até a indicação de expressões intensas de sentimento nos processos dolorosos. Retratam de forma concomitante um sentimento de inadequação no trato da morte, ou um apego, muitas vezes considerado pelos entrevistados como mórbido, ao que se foi. Junto com expressões intensas de individualização, mantém e parecem conservar traços de uma rede tradicional, que busca manter os rituais ligados à morte sob controle de instâncias mais pessoalizadas, como a religião e a família.

Belo Horizonte, segundo dados da pesquisa, encontra-se no interior de um processo mais geral de individualização das relações sociais na sociabilidade contemporânea brasileira, comum a todas as vinte e sete capitais de estado pesquisadas. A fotografia mortuária parece passar por um processo de declínio na sua publicização, pelos que a praticam, 
correspondendo a apenas $12,86 \%$ dos respondentes. Mas, a existência de profissionais fotógrafos ainda realizando suas atividades através do retrato mortuário, o registro pelos próprios familiares de seus mortos, bem como a retomada nas novas propostas de cemitérios humanizados de departamentos de fotografia especializada, mostram que a prática ainda parece permanecer viva entre os homens comuns, apesar de sua atual suspeição social. ${ }^{12}$

Perguntado ao conjunto dos informantes de Belo Horizonte se já tive acesso a fotografias mortuárias nos álbuns ou coleções de retrato de suas famílias, o número de respostas positivas cresceu e se mostrou bastante significativo, chegando a $67,14 \%$ dos entrevistados. Conforme pode ser visto na Tabela 11 abaixo, este índice se situa na média das respostas por regiões no Brasil, que varia de 42,44\% para a região Sul a $52,14 \%$ para o Nordeste.

\section{Tabela 11 - Cidade, Região e Existência de Fotografias Mortuárias nos Álbuns Familiares}

\begin{tabular}{|c|c|c|c|c|c|c|}
\hline \multirow{2}{*}{ BH/Região /Brasil } & \multicolumn{2}{|c|}{ Não } & \multicolumn{2}{|c|}{ Sim } & \multicolumn{2}{|c|}{ Total } \\
\hline & $\mathrm{N}$ & $\%$ & $\mathrm{~N}$ & $\%$ & $\mathrm{~N}$ & $\%$ \\
\hline Belo Horizonte & 23 & 32,85 & 47 & 67,14 & 70 & $100 \%$ \\
\hline Sudeste & 135 & 52,12 & 124 & 47,88 & 259 & $100 \%$ \\
\hline Sul & 99 & 57,56 & 73 & 42,44 & 172 & $100 \%$ \\
\hline Centro Oeste & 88 & 49,95 & 89 & 50,05 & 177 & $100 \%$ \\
\hline Nordeste & 236 & 47,86 & 257 & 52,14 & 493 & $100 \%$ \\
\hline Norte & 103 & 50,74 & 100 & 49,26 & 203 & $100 \%$ \\
\hline BRASIL & 687 & 52,68 & 617 & 47,32 & 1304 & $100 \%$ \\
\hline
\end{tabular}

O pano de fundo relacional que molda e caracteriza os vieses comportamentais do brasileiro, de que fala Roberto Da Matta, ${ }^{13}$ pode ser exemplificado através do hábito do registro fotográfico dos entes queridos mortos no passado recente da família brasileira, e de Belo Horizonte, aqui, em particular. Este exemplo fica mais claro sobretudo quando na fotografia mortuária não apenas se retrata o morto, mas o morto em relação aos vivos, ou o contrário, os vivos em relação ao morto.

12 Com uma tendência de retomada, não só no Brasil como no mundo ocidental contemporâneo, ver RUBY Retratando os mortos. In: KOURY, M.G.P.(org.). Imagem e Memória. Ensaios em Antropologia Visual. Rio de Janeiro: Garamond, 2001, p.95-112.

13 DA MATTA, Roberto. A Casa e a Rua. Espaço, Cidadania, Mulher e Morte no Brasil. Rio de Janeiro: Guanabara, 1987. 
Estes dados indicam a presença da fotografia mortuária no passado recente de muitas famílias na cidade de Belo Horizonte, e em todo o Brasil, maior do que se esperava encontrar. O que parece colocar o registro da morte como um dos momentos significativos na esfera das relações internas e exteriores à família e à conformação da sociedade brasileira como um todo.

Nela se busca retratar além do corpo morto, o cenário que denota a importância e significação de quem morreu, o enlutamento dos entes queridos e a presença social da comunidade no velório e sepultamento do cadáver. A última lembrança, assim, diagnostica, comprova e consolida as relações e posições sociais, bem como as etiquetas da dor.

Comparado, porém, com os que atualmente imputam a si o costume da fotografia mortuária, nota-se um declínio do hábito, o que parece indicar uma mudança recente no comportamento perante a morte e o morrer no imaginário urbano, apesar de hoje em dia começar a ser estimulado nos novos modelos de cemitérios com visões mais empresariais e com assessoria de psicólogos e serviço social. Este declínio no hábito parece apresentar-se, por outro lado, cheio de ambigüidades característicos de períodos de transição para uma nova forma de sociabilidade com ênfase, cada vez maior, nos processos de individualização.

Ambigüidades, diagnosticadas na sociedade francesa por Philippe Áries, ${ }^{14}$ no decorrer das décadas de 1950 e 1960, que se referem sobretudo à ambivalência das atitudes ao nível individual, e remetem ao enfraquecimento da sensibilidade em relação aos mortos e às formas de comportamento aos que sofreram perdas recentes. Afirma, que uma pessoa ao mesmo tempo em que tem vergonha de falar da morte ou de um morto, e não sabe como proceder nas condolências à família ou a amigos enlutados, compra, sem sentir remorsos, um jazigo para si ou irá por flores no túmulo de um parente querido.

A sociedade brasileira, a partir dos anos de 1970, e principalmente dos anos de 1980, parece viver esse tipo de ambivalência relatada por Ariès para a sociedade francesa pós-segunda guerra mundial. Esse processo ambivalente de individualização perpassa, como demonstram os dados da pesquisa, que todas as capitais dos estados brasileiros, de uma forma quase uniforme, vêm modificando as rotinas tradicionais de comportamento, descrendo junto ao indivíduo comum, sobretudo de classe média, todo um conjunto de padrões ritualísticos.

A fotografia mortuária parece acompanhar as atitudes de retraimento em face da morte e em relação aos mortos, tornando-se aparentemente mórbida ou de cunho patológico, para grande parte dos entrevista-

14 Ver o artigo de ARIĖS, Philippe. La Vie et la Mort chez les Français D'Aujourd'hui. Ethno-Psychologie, v.27, n.1, p.39-44, 1972. 
dos, em Belo Horizonte, e no Brasil. No imaginário atual do homem urbano brasileiro parece disseminar-se a suspeição nas fórmulas rituais de sujeição da dor pessoal do enlutado e da integração do morto às malhas sociais através de uma série de ritos de passagem, acompanhada de um sentimento de vergonha a expressões intensas de sentimento ao nível público, e do modo higiênico no trato dos mortos. ${ }^{15}$

Próprios da fotografia mortuária, a manifestação pública da dor individual e as atitudes de fixação e rememoração acentuada de um ser querido morto, se vêem mescladas por uma condenação velada da dor e das atitudes públicas de permanência dos entes mortos no seio dos vivos, pelo sentimento de solidão individual e de retraimento. De não ter com quem e como expressar a sua dor, expulsa que está para dentro da pessoa. A ambivalência, assim, parece predominar.

Esta ambivalência perpassa também ao hábito da fotografia mortuária. Pode ser sentida, na pesquisa, ao se comparar o número de entrevistados que não costumam fotografar os seus mortos, em relação aos que afirmam possuir fotografias mortuárias nos álbuns fotográficos da família. Na Tabela 12 se verifica que $87,14 \%$ dos entrevistados da cidade de Belo Horizonte afirmam, por vários motivos, não fotografar os seus mortos, contra 74,44\% da região Nordeste e 79,22\% do Brasil. Na Tabela 11, encontram-se $67,14 \%$ dos informantes de Belo Horizonte, contra 52,14\% dos entrevistados do Nordeste e $47,32 \%$ do Brasil que afirmam a existência das fotografias mortuárias nos álbuns de família. Ao procurar relacionar as Tabelas 11 e 12 é possível verificar, de um lado, que o costume de fotografar os entes queridos mortos declina no Brasil, e em Belo Horizonte, ai, em particular. Mas, por outro lado, junto da afirmação recente dos entrevistados de não fotografar os mortos, segundo vários motivos, os habitantes da cidade de Belo Horizonte, tanto quanto os das diversas regiões brasileiras e do Brasil, como um todo (Tabela 11), não se constrangem em afirmar a posse ou a existência de fotografias mortuárias nos seus álbuns ou coleções privadas de fotografia familiar. Este fato pode ser compreendido, como hipótese de trabalho, na medida em que a existência de fotografias de entes queridos mortos na família, agora desvendados, pertencerem ao passado, ainda que um passado recente, sem aparentemente afetar o presente individual de quem o afirma. Não parecendo, assim, constranger o informante, ao passo que a informação sobre o uso, na atualidade, poderia levar a significar, entre outros aspectos, falta de urbanidade ou de civilidade. Elementos que afetariam sobretudo os anseios do parecer moderno da classe média, de Belo Horizonte, ou brasileira.

15 Ver a questão de forma mais aprofundada em KOURY, M.G.P. Sociologia da Emoção: O Brasil urbano sob a ótica do luto. Petrópolis: Vozes, 2003; e KOURY, M.G.P. Amor e Dor: Ensaios em Antropologia Simbólica. Recife: Bagaço, 2005. 
Tabela 12 - Não Costuma Fotografar os Mortos

\begin{tabular}{|c|c|c|c|c|}
\hline \multicolumn{5}{|c|}{ Tabela 12 - Não Costuma Fotografar os Mortos } \\
\hline Costuma Fotografar os Mortos & Não & ografa & & \\
\hline Cidade / Região & $\mathrm{N}$ & $\%$ & $\mathrm{~N}$ & $\%$ \\
\hline Belo Horizonte & 61 & $87,14 \%$ & 70 & $100 \%$ \\
\hline Sul & 143 & $83,14 \%$ & 172 & $100 \%$ \\
\hline Sudeste & 225 & $86,87 \%$ & 259 & $100 \%$ \\
\hline Centro Oeste & 139 & $78,53 \%$ & 177 & $100 \%$ \\
\hline Nordeste & 367 & $74,44 \%$ & 493 & $100 \%$ \\
\hline Norte & 159 & $78,33 \%$ & 203 & $100 \%$ \\
\hline BRASIL & 1033 & 79,22 & 1304 & $100 \%$ \\
\hline
\end{tabular}

Uma costura relacional que habitava e habilitava hábitos familiares antigos, de bases rurais, e que foram desprezados na contemporaneidade pelos informantes, cada vez mais urbanizados e sujeitos a uma uniformidade de processos informativos pelos media, embora detenham ainda a posse de retratos mortuários ou possam comprovar sua existência nas coleções fotográficas familiares. O retraimento, assim, é estabelecido com o hoje e não com o passado.

Comprovação que encaminha, ainda, mesmo que como um atestado melancólico, às tradições familiares. Ou que leva para as intrincadas redes relacionais do passado recente da família brasileira, e de Belo Horizonte, aqui, em particular. Redes ainda vivenciadas, mesmo que de forma redefinida, nas teceduras políticas e sociais de muitas famílias extensas, principalmente, as mais tradicionais de cada estado da federação.

Embora não mais vividas na cotidianidade dos entrevistados, parecem remeter às características formadoras e de consolidação dos laços de parentesco, e social anterior, hoje perdidas, ou em processo de exclusão. Agora vividas sob a ótica da morbidez, ou como fixação de uma nova temporalidade e de uma nova moral, no espaço singular e solitário do homem urbano no Brasil atual.

\section{Conclusão}

A fotografia mortuária, assim, como as demais formas de fotografias de cunho privado dos álbuns de família, possuiu na sociedade brasileira e ocidental um lado referencial de lembrança do que se foi, como uma espécie de evocação sentimental do morto. Teve, também, um outro lado importante que foi o de demonstração social do prestígio do morto e da família a que fez parte. Até os anos trinta do século XX, no Brasil, este tipo de fotografia era feito por um fotografo profissional e, um pouco dife- 
rente das primeiras décadas do século vinte, nos anos cinqüenta já incorporava um elenco maior de camadas sociais, principalmente as chamadas classes médias, pelo barateamento do seu custo.

Dos anos cinqüenta em diante, a fotografia se populariza mais e mais, chegando aos dias atuais a todas as classes e categorias sociais, sobretudo urbanas. Os registros deixam de ser feitos, na maior parte das vezes por fotógrafos profissionais e são fotógrafos amadores que passam a registrar o cotidiano pessoal e familiar. É interessante verificar que esse momento de passagem da democratização da fotografia, trouxe também pari passu o declínio da fotografia mortuária.

Hoje, com o estabelecimento de empresas cemiteriais, o uso da fotografia mortuária profissional começa a ser mais uma vez objetivada como um produto de mercado da morte, ainda estando longe, porém, de sua plena aceitação mercadológica pelos consumidores.

A fotografia, contudo, continua ainda a seguir um ritual de registros de momentos significativos na vida da pessoa e da família. Nascimento, aniversários, formatura, casamentos, filhos que chegam, morte, são ainda elementos privilegiados do registro da fotografia de uso íntimo, como para celebrar, e fazer lembrar, a pontuação de uma vida, para si mesmo e para os seus e os outros. ${ }^{16}$

No caso da fotografia mortuária, porém, ela passou por uma reconfiguração. A forma de seu uso caminhou junto à organização dos chamados santinhos, cartões de agradecimento e para lembrança dos mortos familiares, a partir dos anos sessenta do século XX. Nos santinhos, quando a fotografia é mantida, é o sujeito em vida que é colocado. A face da morte deixou de ser o elemento fundamental para assegurar a presença do morto ao outro, agora é a face da vida, do sujeito em vida que passa a fazer parte dos rituais de lembranças publicizados. ${ }^{17}$

Este elemento é significativo no processo de mascaramento da morte e sua transfiguração social em elemento mórbido. Os anos de 1970, e principalmente os de 1980 em diante, processam rapidamente uma transformação nos usos e costumes ligados a uma tradição relacional que perdurou por séculos na sociabilidade brasileira, em seu lugar ganha espaço o indivíduo social e as relações impessoais de troca, de desempenho e concorrência social, sobretudo no Brasil urbano.

Uma descrença crescente nos costume, e uma busca de desprendimento do passado parece marcar e configurar esse novo homem surgido no Brasil urbano contemporâneo. A civilidade passa a ser a de uma atitude de aparente indiferença e insensibilidade para com o outro

16 Ver sobre o assunto os trabalhos de LEITE, Miriam Moreira. Retratos de Família. São Paulo: Edusp, 1993; e LIRA, Bertrand de Sousa. Fotografia na Paraíba. João Pessoa: Ed. Universitária, 1997.

17 Ver KOURY, M.G.P. "Fotografia, Sentimento e Morte no Brasil". In: KOURY, MGP (org.) Imagens \& Ciências Sociais. João Pessoa: Ed. Universitária, 1998, p.49-66. 
e para o conjunto de rituais da sociedade tradicional. A morte e os mortos, nesse sentido, buscam ser vistos de um modo higiênico. Passa-se a condenar uma fixação por um tempo maior, além de uma semana, para expressão da dor em relação aos mortos particulares, bem como uma desaprovação e um constrangimento tácito a expressões intensas de sentimento.

Essa negação da emoção e o lidar higiênico com a morte fazem declinar e quase desaparecer a fotografia mortuária, do lado público dos álbuns de família. A fotografia mortuária parece fazer parte de um passado ingênuo, onde se privilegiava o que passou em detrimento do tempo presente e da construção do futuro.

Resta saber como agirá a nova entrada profissional da fotografia mortuária nos produtos da morte vendidos nas empresas cemiteriais no mundo ocidental, nas principais cidades brasileiras e, aqui, em Belo Horizonte, de modo particular. Ofertada ainda timidamente, como um produto de grife, a fotografia mortuária pode reaparecer como mais um adereço da individualização e do individualismo, não mais apenas como um registro de memória familiar e social, mais como uma singularidade da moda que, individualiza, dá poder a quem a possui. 